\title{
Constitutive Expression of the $\alpha 10$ Nicotinic Acetylcholine Receptor Subunit Fails to Maintain Cholinergic Responses in Inner Hair Cells After the Onset of Hearing
}

\author{
Julián Taranda, ${ }^{1}$ Jimena A. Ballestero, ${ }^{1}$ Hakim Hiel,${ }^{2}$ Flavio S. J. de Souza, ${ }^{1}$ Carolina Wedemeyer, ${ }^{1}$ \\ M. Eugenia Gómez-Casati, ${ }^{1}$ Marcela Lipovsek, ${ }^{1}$ Douglas E. Vetter, ${ }^{4}$ Paul A. Fuchs, ${ }^{2}$ \\ Eleonora Katz, ${ }^{1,3}$ and A. Belén Elgoyhen ${ }^{1,5}$ \\ ${ }^{1}$ Instituto de Investigaciones en Ingeniería Genética y Biología Molecular, Consejo Nacional de Investigaciones Científicas y \\ Técnicas, Buenos Aires 1428, Argentina \\ ${ }^{2}$ Department of Otolaryngology, Head and Neck Surgery, and Center for Hearing and Balance, The Johns Hopkins University \\ School of Medicine, Baltimore, MD 21205-2195, USA \\ ${ }^{3}$ Departamento de Fisiología, Biología Molecular y Celular, Facultad de Ciencias Exactas y Naturales, Universidad de Buenos \\ Aires, Buenos Aires 1428, Argentina \\ ${ }^{4}$ Deptartment of Neuroscience, Tufts University School of Medicine, Boston, MA 02111, USA \\ ${ }^{5}$ Departamento de Farmacología, Facultad de Medicina, Universidad de Buenos Aires, Buenos Aires 1121, Argentina
}

Received: 31 March 2009; Accepted: 4 May 2009; Online publication: 19 May 2009

\begin{abstract}
Efferent inhibition of cochlear hair cells is mediated by $\alpha 9 \alpha 10$ nicotinic cholinergic receptors (nAChRs) functionally coupled to calcium-activated, small conductance (SK2) potassium channels. Before the onset of hearing, efferent fibers transiently make functional cholinergic synapses with inner hair cells (IHCs). The retraction of these fibers after the onset of hearing correlates with the cessation of transcription of the Chrna10 (but not the Chrna9) gene in IHCs. To further analyze this developmental change, we generated a transgenic mice whose IHCs constitutively express $\alpha 10$ into adulthood by expressing the $\alpha 10 \mathrm{cDNA}$ under the control of the Pou 4$\} 3$ gene promoter. In situ hybridization showed that the $\alpha 10$ mRNA is expressed in IHCs of 8-week-old transgenic mice, but not in wild-type mice. Moreover, this mRNA is translated into a functional protein, since IHCs from P8-P10 $\alpha 10$ transgenic mice backcrossed to a $\mathrm{Chma10}^{-1}$ background (whose IHCs
\end{abstract}

Julián Taranda and Jimena A. Ballestero equally contributed.

Correspondence to: A. Belén Elgoyhen - Instituto de Investigaciones en Ingeniería Genética y Biología Molecular · Consejo Nacional de Investigaciones Científicas y Técnicas · Buenos Aires 1428, Argentina. Telephone: +54-11-47832871; fax: +54-11-47868578; email: elgoyhen@ dna.uba.ar have no cholinergic function) displayed normal synaptic and acetylcholine (ACh)-evoked currents in patch-clamp recordings. Thus, the $\alpha 10$ transgene restored nAChR function. However, in the $\alpha 10$ transgenic mice, no synaptic or ACh-evoked currents were observed in P16-18 IHCs, indicating developmental downregulation of functional nAChRs after the onset of hearing, as normally observed in wild-type mice. The lack of functional ACh currents correlated with the lack of SK2 currents. These results indicate that multiple features of the efferent postsynaptic complex to IHCs, in addition to the nAChR subunits, are down-regulated in synchrony after the onset of hearing, leading to lack of responses to ACh.

Keywords: nicotinic cholinergic receptors, efferent medial olivocochlear, SK2 channel, acetylcholine, transgenic mice

\section{INTRODUCTION}

Efferent inhibition of cochlear hair cells is mediated by the release of acetylcholine (ACh) from neurons originating in the superior olivary complex of the brainstem. In the mature cochlea, the medial olivoco- 
chlear (OC) efferent pathway projects to outer hair cells (OHCs) where large synaptic contacts are formed (Guinan 1996). Activation of this pathway reduces cochlear sensitivity through the action of ACh on nicotinic receptors (nAChRs) at the base of OHCs. Significant progress has been made in defining the cellular mechanisms of hair cell inhibition: $\alpha 9$ and $\alpha 10$ nAChR subunits arrange into a pentameric assembly with a likely $(\alpha 9)_{2}(\alpha 10)_{3}$ stoichiometry (Elgoyhen et al. 1994, 2001; Lustig et al. 2001; Plazas et al. 2005; Sgard et al. 2002) and activation of the $\alpha 9 \alpha 10$ nAChR leads to an increase in intracellular $\mathrm{Ca}^{2+}$ and the subsequent opening of small conductance $\mathrm{Ca}^{2+}$-activated $\mathrm{K}^{+}$(SK2) channels, thus leading to hyperpolarization of hair cells (Dulon et al. 1998; Fuchs and Murrow 1992; Housley and Ashmore 1991; Oliver et al. 2000).

Although adult inner hair cells (IHCs) receive very few (if any) direct axosomatic contacts from efferent fibers, before the onset of hearing [until about postnatal (P) day 12 in rats and mice], a transient efferent innervation is found on IHCs (Simmons 2002; Katz et al. 2004). These transient efferent axosomatic synapses with IHCs most likely play a role in the modulation of the $\mathrm{Ca}^{2+}$ spiking activity, a characteristic of immature IHCs, which may drive rhythmic or bursting activity of neurons at higher levels of the auditory pathway (Glowatzki and Fuchs 2000). Previous studies have suggested that this transient efferent innervation may play a role in the ultimate functional maturation of cochlear hair cells (Simmons 2002). Most impressively, surgical lesion of the efferent nerve supply causes kittens to fail to develop normal hearing (Walsh et al. 1998).

With maturation of the cochlea, a number of changes in the expression of voltage-gated channels tend to reduce IHC spiking (Kros et al. 1998; Marcotti et al. 2003a, b). These changes signal the transformation from a developing epithelium with active formation of synaptic contacts to a sensing epithelium where receptor potentials represent the mechanical input in a graded fashion. These changes are accompanied by the loss of direct efferent innervation to IHCs, and this is directly correlated to the cessation of transcription in IHCs of the gene coding for the $\alpha 10$ (Chrna10) but not the $\alpha 9$ (Chrna9) nAChR subunit (Elgoyhen et al. 1994, 2001; Morley and Simmons 2002; Simmons 2002). In fact, Chrna9 continues to be transcribed into adult stages (Elgoyhen et al. 1994). To further analyze this critical developmental change near the onset of hearing, we generated a transgenic mice whose IHCs constitutively express $\alpha 10$ into adulthood by expressing the $\alpha 10$ cDNA under the control of the mouse Pou $4 f 3$ gene promoter, a hair cell transcription factor (Erkman et al. 1996). We reasoned that if the lack of responses to ACh after the onset of hearing was due to the cessation in transcription of Chrma10, constitutive expression of the $\alpha 10$ subunit would result in functional receptors. However, ACh sensitivity was lost on schedule, as in wild-type animals. Thus, we found that expression of the $\alpha 10 \mathrm{nAChR}$ subunit into adult ages is not sufficient to sustain cholinergic function, and efferent innervation, of IHCs after the onset of hearing.

\section{MATERIALS AND METHODS}

\section{Generation of Pou $4 f 3-\alpha 10$ transgenic mice}

The Pou $4 f 3-\alpha 10$ transgenic mice were generated using a construct like that previously engineered to drive hair cell expression of Cre recombinase (Sage et al. 2006). As shown in Figure $1 \mathrm{~A}$, a 1.5-kb fragment containing the cDNA encoding the $\alpha 10$ nAChR (Elgoyhen et al. 2001) was subcloned into pSP73 (Promega Corp, Madison, WI, USA). A 9-kb portion of the $5^{\prime}$ upstream region of the mouse Pou $4 f 3$ gene (L. Erkman and G. Rosenfeld, University of California at San Diego, La Jolla) was introduced upstream of the $\alpha 10$ cDNA and used to drive $\alpha 10 \mathrm{nAChR}$ subunit expression. A $\beta$-globin intronic sequence of $600 \mathrm{bp}$ was blunt-ligated to the $5^{\prime}$ end of the $\alpha 10$ insert and a Flag tag (encoding the sequence DYKDDDDK) was inserted before the stop codon of the $\alpha 10$ sequence. A human growth hormone polyA initiation sequence of 580 was ligated to the $3^{\prime}$ end of the $\alpha 10$ insert. The construct was verified by sequencing. The Pou $4 f 3-\alpha 10$ transgene was released by $C l a \mathrm{I}$ digestion and used to generate the Pou $4 f 3-\alpha 10$ transgenic mouse line (with a B6CB5 background, a hybrid between C57BL/6J and CBA/J strains) by using standard pronuclear injection techniques (Young et al. 1998). All animal work was conducted using procedures reviewed and approved by the Institutional Animal Care and Use Committees of INGEBI and were conducted in accordance with the National Institutes of Health Guide for the Care and Use of Laboratory Research Animals.

\section{Genotyping}

For transgenic genotyping, primers tg $\alpha 10 \quad \beta$-globin $\left(5^{\prime}\right.$-CATGAGGGTCCATGGTGATAC- $\left.3^{\prime}\right)$ and $\operatorname{tg} \alpha 10$ Pou 4 f3 (5'-GCATCAGGCTCTCAGATGGCG-3') were used, producing a 494-bp fragment (Fig. 1B). Polymerase chain reaction (PCR) was performed using $94^{\circ} \mathrm{C}$ for $2 \mathrm{~min}$ followed by $94^{\circ} \mathrm{C}$ for $30 \mathrm{~s}, 58^{\circ} \mathrm{C}$ for $1 \mathrm{~min}$, and $72^{\circ} \mathrm{C}$ for $1.5 \mathrm{~min}$ for 30 cycles with $20 \mathrm{ng}$ of genomic DNA obtained from tail biopsies, buffer Mix D (Epicentre, Madison, WI, USA), and Qiagen Taq polymerase (Qiagen, Valencia, CA, USA). The genotyping of the $\mathrm{ChrnalO}^{-/}$mice was performed as previously described (Vetter et al. 2007). 
A

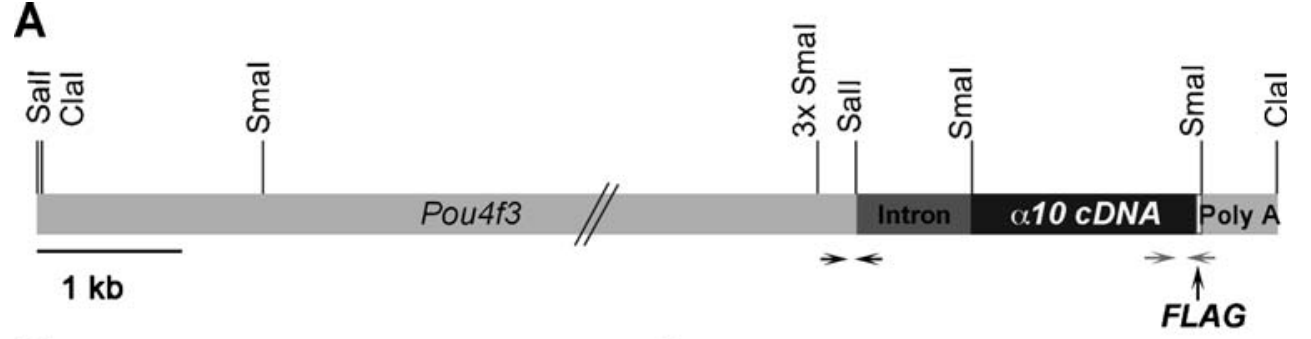

B
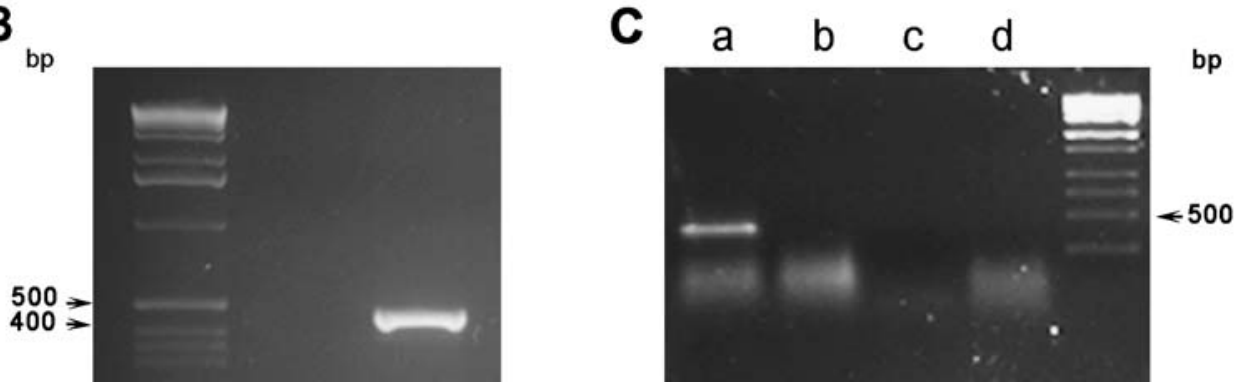

FIG. 1. Genetic engineering, genotyping, and RNA expression of the Pou4f3- $\alpha 10$ transgene. A Map of the transgene construct. Pou4f3, 9-kb portion of the $5^{\prime}$ upstream promoter region of the Pou $4 f 3$ gene; intron, 600 -bp $\beta$-globin intronic sequence; $\alpha 10$ cDNA, entire coding region plus $5^{\prime}$ and $3^{\prime}$ untranslated regions of the $\alpha 10 \mathrm{nAChR}$ subunit with a FLAG tag before the stop codon; polyA, 580-bp human growth hormone initiation sequence. B Routine genotyping of Pou4f3- $\alpha 10$ transgenic mice performed by PCR from isolated tail biopsy tissue

\section{Reverse transcriptase PCR}

Eight-week-old mice were killed, the cochleae removed, and immediately frozen in liquid nitrogen. For each genotype, total RNA was extracted using Trizol reagent (Invitrogen, Buenos Aires, Argentina) following the manufacturer's instructions after grinding the tissue in a TH-1 homogenizer (OMNI, Marietta, Gainsville) and centrifuging at $12,000 \times g$ at $4^{\circ} \mathrm{C}$ to remove bone fragments. A total of $1 \mu \mathrm{g}$ of RNA was used to reverse transcribe using Superscript II reverse transcriptase (Invitrogen) and oligo dT (Invitrogen). One microliter of this reaction was used to amplify the transgenic $\alpha 10$ cDNA using one amplimer that anneals to the FLAG sequence (5'CCATGGTCACATTCTCCACA- $3^{\prime}$ ) and another to the $\alpha 10$ cDNA sequence (5'-CTTGTCATCGTCGTCCTTGTAGTC-3'). In transgenic mice, a 446-bp fragment was obtained.

\section{In situ hybridization}

In situ hybridization experiments used previously published protocols (Hiel et al. 1996). Briefly, the temporal bones of 8-week-old mice were fixed, decalcified, and embedded for cryosectioning. Postfixed, acetylated, and dehydrated $14-\mu \mathrm{m}$ cryosections were hybridized with ${ }^{35}$ S-labeled riboprobe (989 bp; $1.2 \times$ $10^{6} \mathrm{cpm} /$ slide) for $16 \mathrm{~h}$ at $56^{\circ} \mathrm{C}$. After high-stringency

genomic DNA samples and amplimers that anneal at the Pou4f3 and the intronic sequences (black arrows in A). A representative gel indicating no band in a wild-type mice and a positive band in a Pou4f3- $\alpha 10$ transgenic. C RT-PCR from transgenic cochleae indicating a positive band of $446 \mathrm{bp}$ in transgenic mice using amplimers that anneal at the $\alpha 10$ cDNA and the FLAG sequence (gray arrows in A). Lane a positive; lane $b$ control minus reverse transcriptase; lane $c$ control minus oligo dT; lane $d$ control minus RNA.

washes and dehydration, tissue sections were coated with photographic emulsion NBT-2 (Eastman Kodak, Rochester, NY, USA) and developed for $2-5$ weeks at $4^{\circ} \mathrm{C}$. Relative expression levels for $\alpha 10$ mRNA in OHCs and IHCs were compared by counting grains in a box placed over selected regions of cochlear cross-sections. Background counts were repeatedly collected, averaged, and subtracted for each crosssection. Labeled sections from base, middle, and apical cochlear turns were obtained from one wildtype (five sections) and two $\alpha 10$ Pou $4 f 3-\alpha 10$ transgenic mice (six sections).

\section{Electrophysiological recordings from cochlear hair cells}

Mice were killed by decapitation. All experimental protocols were carried out in accordance with the AVMA Guidelines on Euthanasia (June 2007). Apical turns of the organ of Corti were excised from mice and used within $3 \mathrm{~h}$. Day of birth was considered postnatal day 0, P0. Cochlear preparations were mounted under a Leica DMLFS microscope (Leica Microsystems, Wetzlar, Germany) and viewed with differential interference contrast using a $40 \times$ water immersion objective and a Hamamatsu C7500-50 camera with contrast enhancement (Hamamatsu, Hamamatsu City, Japan). Methods to record from IHCs 
were essentially as described previously (Glowatzki and Fuchs 2000; Oliver et al. 2000).

Briefly, IHCs were identified visually with the $40 \times$ objective and during recordings by the size of their capacitance (7 to $12 \mathrm{pF}$ ) and their characteristic voltage-dependent $\mathrm{Na}^{+}$and $\mathrm{K}^{+}$currents (Kros et al. 1998). Some cells were removed to access IHCs, but mostly, the pipette moved through the tissue under positive pressure. The extracellular solution was as follows (in $\mathrm{mM}$ ): $155 \mathrm{NaCl}, 5.8 \mathrm{KCl}, 1.3 \mathrm{CaCl}_{2}, 0.9$ $\mathrm{MgCl}_{2}, 0.7 \mathrm{NaH}_{2} \mathrm{PO}_{4}, 5.6$ D-glucose, and 10 HEPES buffer, $\mathrm{pH}$ 7.4. The pipette solution contained (in $\mathrm{mM}): 150 \mathrm{KCl}, 3.5 \mathrm{MgCl}_{2}, 0.1 \mathrm{CaCl}_{2}, 5$ ethyleneglycolbis ( $\beta$-aminoethyl ether)- $N, N, N^{\prime}, N^{\prime}$-teraacetic acid (EGTA), 5 HEPES buffer, $2.5 \mathrm{Na}_{2}$ ATP, pH 7.2 (KClEGTA saline). Solutions containing ACh or high $\mathrm{K}^{+}$ were applied by a gravity-fed multichannel glass pipette $(\sim 150-\mu \mathrm{M}$ tip diameter) positioned about $300 \mu \mathrm{M}$ from the recorded cell. All working solutions containing either $\mathrm{ACh}$ or elevated $\mathrm{K}^{+}$or both were made up in a saline containing low $\mathrm{Ca}^{2+}(0.5 \mathrm{mM})$ and no $\mathrm{Mg}^{2+}$ so as to optimize the experimental conditions for measuring currents flowing through the $\alpha 9 \alpha 10$ receptors (Weisstaub et al. 2002).

Recording pipettes, 1.2-mm I.D, had resistances of 5-8 M $\Omega$. Currents in IHCs were recorded in the whole-cell patch-clamp mode with an Axopatch 200B amplifier, low-pass-filtered at $2-10 \mathrm{kHz}$, and digitized at $5-20 \mathrm{kHz}$ with a Digidata 1322A board (Molecular Devices, California, USA). Recordings were made at room temperature $\left(22-25^{\circ} \mathrm{C}\right)$. Holding potentials were not corrected for liquid junction potentials or for the voltage drop across the uncompensated series resistance.

\section{RESULTS}

IHCs of Pou $4 f 3-\alpha 10$ mice express $\alpha 10$ mRNA after the onset of hearing

It has been reported that the Pou $4 f 3$ transcription factor is expressed in hair cells from early embryonic until adult stages (Erkman et al. 1996) and that Cre expression driven by the Pou 43 promoter starts as early as embryonic day 13.5 in a transgenic mouse (Sage et al. 2006). Thus, the use of the Pou 43 promoter has become a useful tool for transgenic expression of genes in cochlear hair cells. The generation of a transgenic mouse in which the expression of the $\alpha 10 \mathrm{cDNA}$ is driven by Pou $4 f 3$ is explained in "Materials and methods", the construct shown in Figure 1A and genotyping in Figure 1B. In order to assess Pou $4 f 3-\alpha 10$-driven expression of $\alpha 10$ RNA, reverse transcriptase PCR (RT-PCR) was performed from total RNA extracted from 8-week-old mice. As shown in Figure 1C, a 446-bp fragment was obtained in Pou $4 f 3-\alpha 10$ transgenic mice. Since one of the amplimers anneals to the FLAG sequence, this fragment can only derive from the RNA that has been correctly transcribed from the $\alpha 10$ transgenic cDNA. Amplification from genomic DNA is precluded since no band was observed in the control reaction without reverse transcriptase (lane b). Lanes $\mathrm{c}$ and $\mathrm{d}$ are control reactions, minus oligo dT and minus RNA, respectively.

To establish a hair cell localization of the transgenic $\alpha 10$ RNA, in situ hybridization was performed using a $\alpha 10$ riboprobe. As previously reported (Elgoyhen et al. 2001; Morley and Simmons 2002) and as shown in Figure 2A, wild-type mice express $\alpha 10$ in the $\mathrm{OHC}$ but not in the IHC region after the onset of hearing. However, in Pou4f3- $\alpha 10$ transgenic mice, silver grains were observed both in OHCs and IHCs of 8-week-old mice (Fig. 2B), indicating that the signal observed by RT-PCR most likely arises from the expression of the transgenic $\alpha 10 \mathrm{RNA}$ in the hair cells. Although in OHCs one cannot distinguish the transgenic versus the endogenous expression, in the IHCs, the signal can only arise from $\alpha 10$ RNA derived from the successful expression of the Pou $4 f 3-\alpha 10$ transgene, since wild-type IHC do not express $\alpha 10$ at this adult developmental stage (Fig. 2A; Elgoyhen et al. 2001; Morley and Simmons 2002).

Backcross of the Pou $4 f 3-\alpha 10$ to a $\alpha 10$ nAChR knockout background restores ACh responses and synaptic currents before the onset of hearing

In order to learn whether the transgenic $\alpha 10 \mathrm{RNA}$ is effectively translated into a functional protein, Pou $4 \mathrm{f3}$ $\alpha 10$ transgenic mice were backcrossed into a Chrna10 null background. It has been reported that $\mathrm{Chrna10}^{-/}$ mice lack responses to ACh and the synaptic cholinergic currents observed in normal neonatal mice before the onset of hearing (Vetter et al. 2007). Therefore, we reasoned that responses to ACh in Pou $4 f 3-\alpha 10 \times$ Chrna10 ${ }^{-1}$ would only be observed if the $\alpha 10$ transgene was translated into a $\alpha 10$ protein subunit that restored normal function when co-assembled with the endogenous $\alpha 9$ subunit.

As previously reported (Vetter et al. 2007) and a representative trace shown in Figure 3A, IHCs isolated from $\mathrm{ChrnalO}^{+/+}$mice at P8-9, a developmental stage when IHCs are transiently innervated by OC terminals (Glowatzki and Fuchs 2000; Katz et al. 2004; Simmons 2002), robustly respond to ACh, exhibiting inward currents at $-90 \mathrm{mV}(250 \pm 57 \mathrm{pA}, n=3)$. In contrast, no response to $1 \mathrm{mM} \mathrm{ACh}(n=0 / 7$ cells tested $)$ is detected in IHCs from Chrna10 ${ }^{-/}$mice (Fig. 3A, middle panel). As shown in Figure 3A (right panel), the backcrossing of the Pou 4$\}-\alpha 10$ transgenic mice into the $\alpha 10$ null background restored the normal 

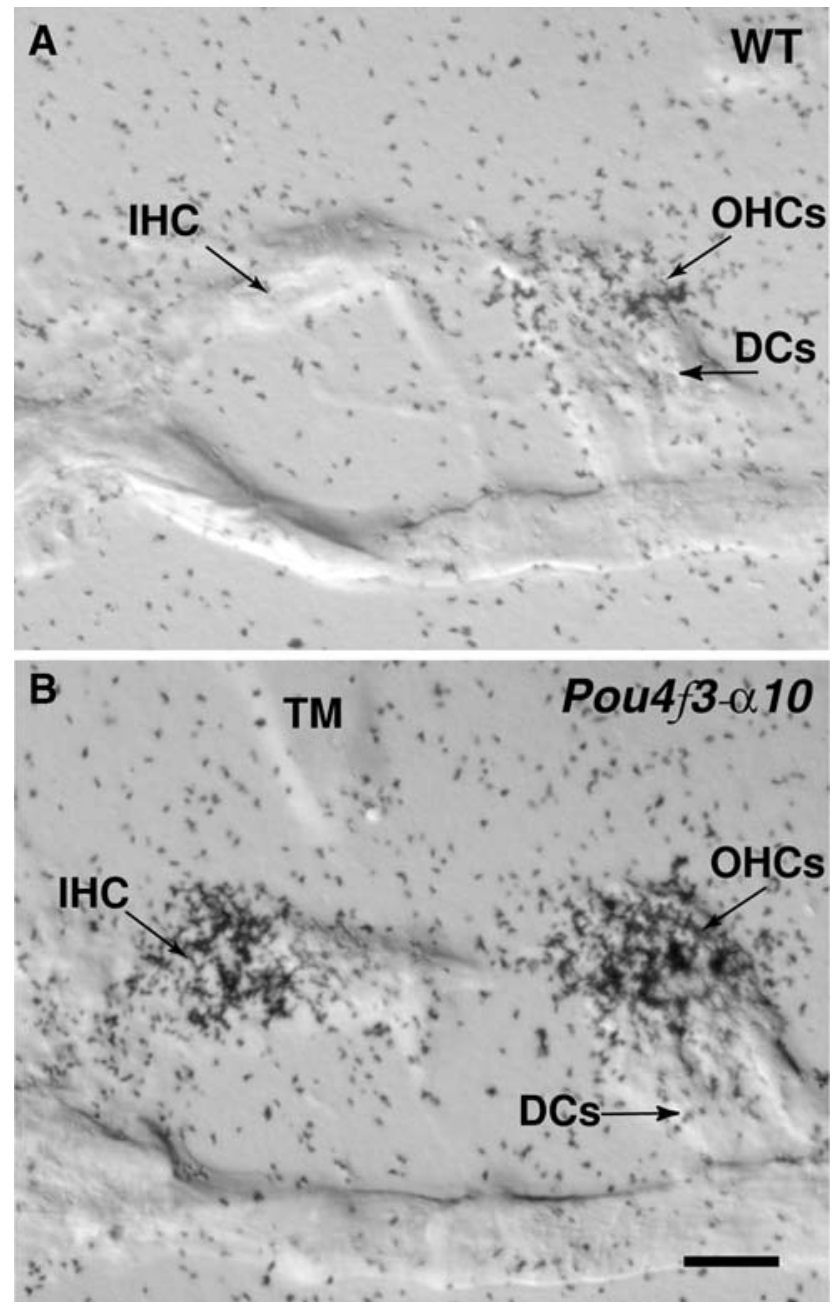

FIG. 2. Transgenic $\alpha 10$ RNA is found in the IHC region after the onset of hearing. A In situ hybridization showing that silver grains are only observed in the $\mathrm{OHC}$ region of 8-week-old wild-type mice. B In Pou 4 f3- $\alpha 10$ transgenic cochleae of 8-week-old mice, staining is observed both in the $\mathrm{OHC}$ and $\mathrm{IHC}$ region. Grain counts were collected from five wild-type and six Pou4f3- $\alpha 10$ transgenic cochlear sections. Wild-type IHC grain counts were not different from background ( $\sim 50$ grains), while there were $212 \pm 14$ grains over wild-type OHCs after subtracting background. In the Pou4f3- $\alpha 10$ transgenic cochlear sections grain counts over IHCs were $308 \pm 60$, not significantly different ( $p=0.59$, unpaired two-tailed $t$ test) from those over OHCs, $259 \pm 55(n=6)$ after subtracting background $(\sim 50)$. Thus, there was consistently and significantly enhanced expression of $\alpha 10$ mRNA in adult Pou $4 f 3-\alpha 10$ transgenic IHCs. TM tectorial membrane, DCs Deiter's cells. A representative in situ from the basal turn of the cochlea is shown.

inward responses to $1 \mathrm{mM}$ ACh ( $V_{\text {hold }}-90 \mathrm{mV}$ ) at P8-9 in all IHCs tested. The shape and magnitude of the response observed in Pou4f3- $\alpha 10 \times \mathrm{Chma10}^{-1}(298 \pm 24$ $\mathrm{pA}, n=3$ cells, 3 mice) did not differ from that observed in wild-type mice.

IHCs from Chrna10 ${ }^{+/+}$mice also exhibit outward currents at $-40 \mathrm{mV}(281 \pm 47 \mathrm{pA}, n=3$; Fig. 3B), indicating functional coupling to SK2 channels (Katz et al. 2004; Vetter et al. 2007), whereas no response is found at $-40 \mathrm{mV}$ in IHCs from Chrna10 ${ }^{-1-}$ mice ( $n=0 / 8$ cells tested; Fig. 3B, middle panel). As shown in Figure 3B (right panel), the backcrossing of the Pou4f3- $\alpha 10$ transgenic mice into the $\alpha 10$ null background restored the normal outward responses to $1 \mathrm{mM}$ ACh (325 $\pm 48 \mathrm{pA}, n=3$ cells, 3 mice) at P8-9 in all IHCs tested.

Finally, when the preparation is superfused with a buffer containing $40 \mathrm{mM} \mathrm{K}{ }^{+}$to depolarize the efferent terminals, thus increasing the frequency of ACh release (Glowatzki and Fuchs 2000; Katz et al. 2004), synaptic currents are observed in IHCs of Chrna10 mice ( $n=3 / 3$ cells tested; Fig. 3C, left panel), but not in IHCs from Chrna10 ${ }^{-/-}$mice $(n=0 / 8$ cells tested; Fig. 3C, middle panel; Vetter et al. 2007). Even when adding $1 \mathrm{mM} \mathrm{ACh}$ in the presence of $40 \mathrm{mM} \mathrm{K}^{+}$, a procedure that enhances small responses to ACh (due to the change in the $\mathrm{K}^{+}$equilibrium potential and the concomitant increase in the driving force for $\mathrm{K}^{+}$ions at the holding voltage of $-90 \mathrm{mV}$; Katz et al. 2004), no responsive IHCs are observed in $\mathrm{Chrna10}^{-1-}$ mice (Fig. 3C, middle panel). When the preparation was superfused with a buffer containing $40 \mathrm{mM} \mathrm{K}^{+}$to depolarize the efferent terminals, synaptic currents were observed in all Pou 4 3- $\alpha 10 \times \mathrm{Chrna10}^{-1}$ IHCs (Fig. 3C, right panel), and the addition of $1 \mathrm{mM}$ $\mathrm{ACh}$ in the presence of $40 \mathrm{mM} \mathrm{K} \mathrm{K}^{+}$produced an inward current similar to that observed in IHCs of $\mathrm{Chrna1O}^{+/+}$mice. Figure 3D shows boxes in $\mathrm{C}$ at an expanded timescale.

Thus, the experiments described so far demonstrate that the Pou $4 f 3-\alpha 10$ transgene is indeed transcribed into RNA and then translated into a functional $\alpha 10$ protein that can assemble with the endogenous $\alpha 9$ subunit, leading to normal ACh responses and synaptic currents.

IHCs of Pou $4 f 3-\alpha 10$ mice fail to respond to ACh and to elicit synaptic currents after the onset of hearing

Since IHCs continue to express the $\alpha 9$ mRNA after the onset of hearing (Elgoyhen et al. 1994) and the Pou 4 f3- $\alpha 10$ transgenic mice shown here constitutively express $\alpha 10$ mRNA even after the onset of hearing, one would expect to find functional $\alpha 9 \alpha 10$ receptors after this critical developmental period if the lack of responses of IHCs to ACh is solely due to the cessation in the expression of Chrnalo.

As shown in Figure 4A, B (upper panels), P9-10 IHCs of Pou4f3- 10 transgenic mice responded to $100 \mu \mathrm{M}$ ACh with outward currents at $-40 \mathrm{mV}$ and inward currents at $-90 \mathrm{mV}$, with overall shape and magnitude $(411 \pm 67 \mathrm{pA}, n=9$ cells, 5 mice and $367 \pm$ $43 \mathrm{pA}, n=9$ cells, 5 mice, respectively) which did not significantly differ $(p>0.05)$ to that observed for wild- 
A

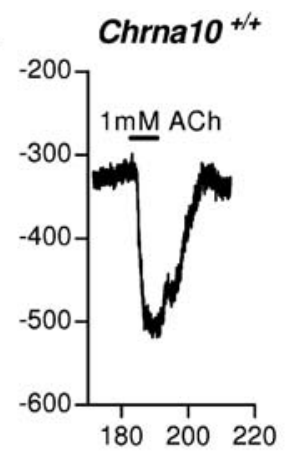

B

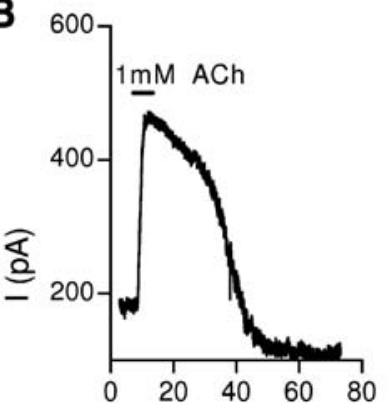

C

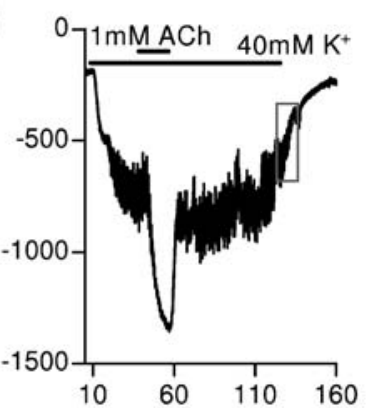

D

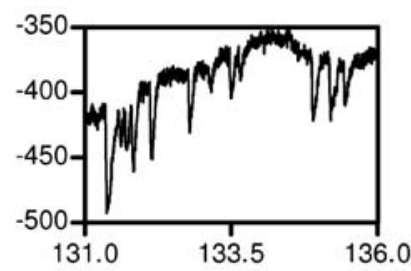

Chrna10\%
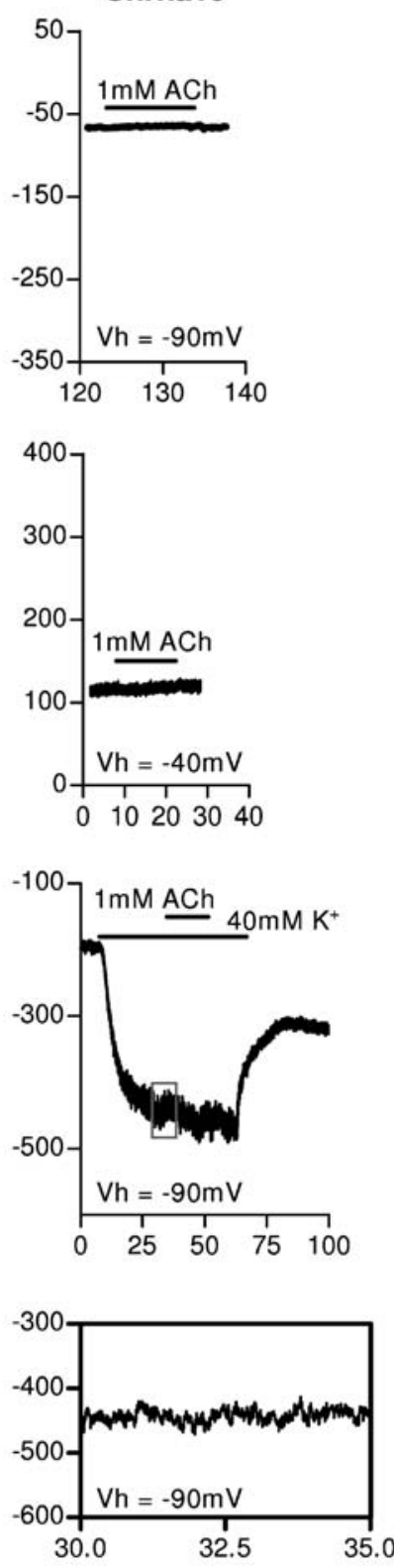

Time (s)
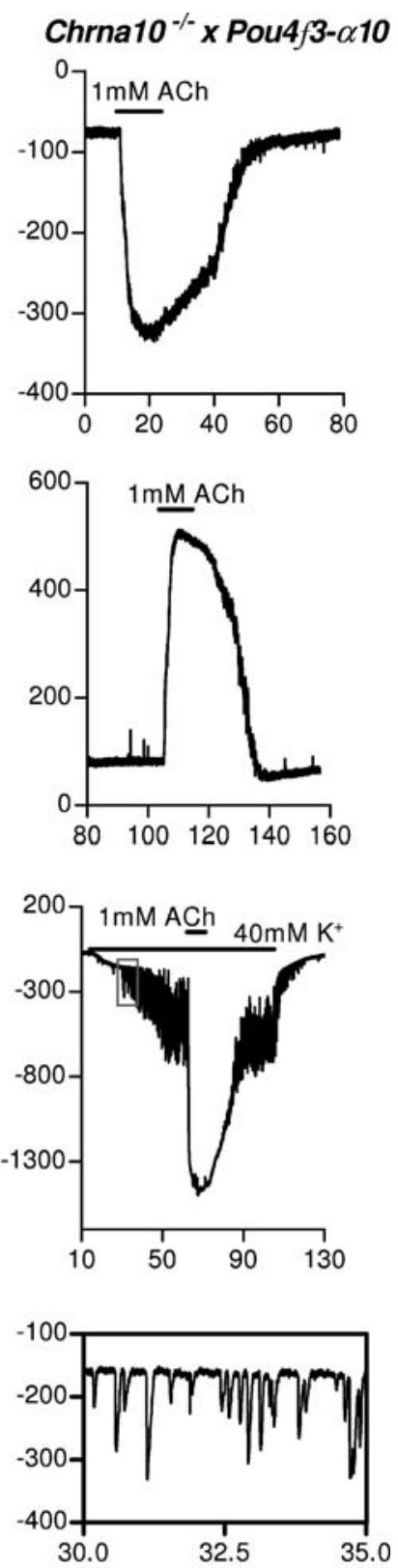

FIG. 3. Functional responses in a Pou $4 f 3-\alpha 10 \times \alpha 10$ nAChR knockout backcross. A Representative responses to $1 \mathrm{mM}$ ACh of IHCs from P89 mice, in Chrna10 ${ }^{+/+}$( $n=3$ cells, 3 mice), Chrna10 ${ }^{-/}$( $n=7$ cells, 3 mice), and Chrna10 ${ }^{-1} \times$ Pou4f3- $\alpha 10$ mice ( $n=3$ cells, 3 mice), $V_{\text {hold }}=$ $-90 \mathrm{mV}$. Note the lack of responses in $\alpha 10$ knockout mice and restoration of responses when $\mathrm{Chrna10^{-1 }}$ are crossed with the Pou4f3$\alpha 10$ transgenic mice. B Same as in A, but at $V_{\text {hold }}=-40 \mathrm{mV}$. C Superfusion of the cells with high potassium $\left(40 \mathrm{mM}\right.$ at $V_{\text {hold }}$ of $-90 \mathrm{mV}$ ) causes a change in the holding current due to the change in the $\mathrm{K}^{+}$equilibrium potential in the three genotypes. In the case of Chrna10 ${ }^{+/+}$( $n=3$ cells, 3 mice), synaptic currents appear on top of the holding current because of the release of ACh from depolarized efferent terminals. Moreover, $1 \mathrm{mM}$ ACh produces an inward current on top of the change in the holding current. No synaptic activity and responses to ACh can be observed in IHCs from Chrna10 ${ }^{-1-}$ ( $n=8$ cells, 3 mice), and this is restored in the Chrna10 $0^{-1} \times$ Pou4f3$\alpha 10$ background ( $n=3$ cells, 3 mice). D Synaptic currents enclosed by the boxes shown in $\mathbf{C}$, plotted at an extended timescale. type mice (366 \pm 63 and $272 \pm 43$ for -40 and $-90 \mathrm{mV}$, respectively, $n=10$ cells, 6 mice, not shown). Moreover, IHCs of P9-10 Pou 4 f3- $\alpha 10$ transgenic mice exhibited synaptic currents when exposed to $40 \mathrm{mM} \mathrm{K}^{+}$saline to depolarize the efferent termi- nals (Fig. 4C, D, upper panel), and the addition of $1 \mathrm{mM}$ ACh in the presence of $40 \mathrm{mM} \mathrm{K}$ produced an inward current at $-90 \mathrm{mV}$ (Fig. 4C, upper panel), as has been previously described for wild-type mice (Vetter et al. 2007). 

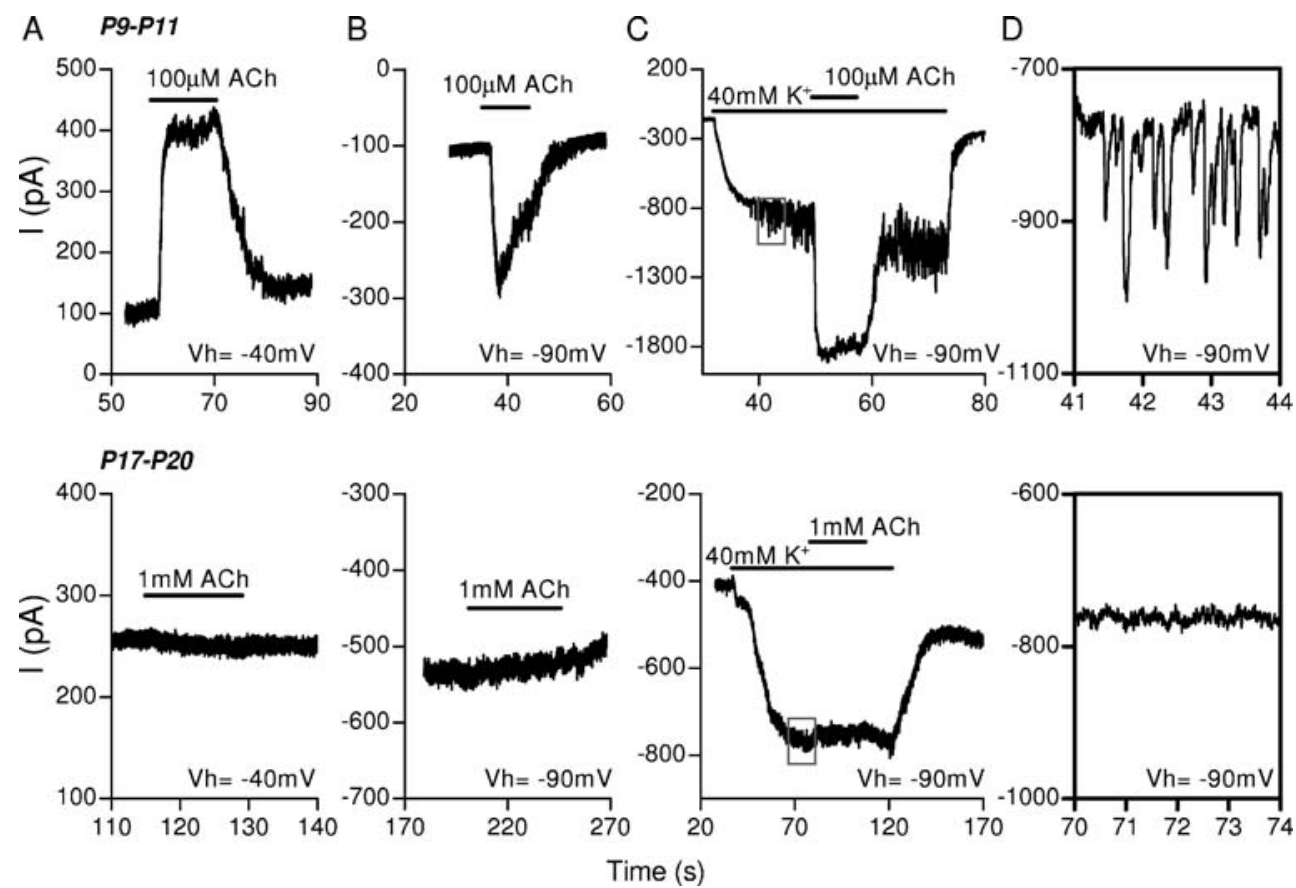

FIG. 4. Lack of $\mathrm{ACh}$ responses in IHCs of Pou4f3- $\alpha 10$ transgenic mice after the onset of hearing. A, B Responses to ACh of IHCs from Pou4f3- $\alpha 10$ transgenic mice at a $V_{\text {hold }}$ of -40 and $-90 \mathrm{mV}$, respectively. Note normal responses before the onset of hearing (upper panels, $n=9$ cells, 5 mice) and lack of responses after the onset of hearing (lower panels, $n=9$ cells, 4 mice). C Superfusion of the cells with high potassium $\left(40 \mathrm{mM}\right.$ at $V_{\text {hold }}$ of $\left.-90 \mathrm{mV}\right)$ causes a change in the holding current due to the change in the $\mathrm{K}^{+}$equilibrium

potential. Before the onset of hearing (upper panels, $n=9$ cells, 5 mice), synaptic currents appear on top of the holding current because of the release of ACh from depolarized efferent terminals, and $1 \mathrm{mM}$ ACh produces an inward current on top of the shift in the holding current. No synaptic activity and responses to $1 \mathrm{mM}$ ACh can be observed in IHCs of Pou4f3- $\alpha 10$ transgenic mice after the onset of hearing (lower panels, $n=9$ cells, 4 mice). D Synaptic currents enclosed by the boxes shown in $\mathbf{C}$, plotted at an expanded timescale.

However, as observed in Figure 4 (lower panels), the constitutive expression of the $\alpha 10$ subunit was not sufficient to maintain functional $\alpha 9 \alpha 10$ receptors after the onset of hearing. Thus, at P17-20, IHCs from Pou $4 f 3-\alpha 10$ mice failed to respond to $1 \mathrm{mM} \mathrm{ACh}$ both at -40 and $-90 \mathrm{mV}$ (Fig. $4 \mathrm{~A}, \mathrm{~B}, \mathrm{n}=9$ cells, 4 mice), failed to exhibit synaptic currents at $40 \mathrm{mM} \mathrm{K} \mathrm{K}^{+}$ (Fig. 4C, D), and failed to respond to $1 \mathrm{mM} \mathrm{ACh}$ under conditions in which the driving force for $\mathrm{K}^{+}$was increased (Fig. 4C).

\section{IHCs of Pou $4 f 3-\alpha 10$ mice lack functional SK currents after the onset of hearing}

The inhibitory nature of the OC synapse in immature IHCs is due to the activation of an SK2 channel after $\mathrm{Ca}^{2+}$ influx through the $\alpha 9 \alpha 10$-containing nAChRs (Glowatzki and Fuchs 2000; Gomez-Casati et al. 2005; Katz et al. 2004). After the onset of hearing, both Chrna10 and SK2 gene expression is down-regulated, and this is correlated with the disappearance of AChevoked responses (Katz et al. 2004). Thus, it appears that the regulation of the transcription of both the Chrna10 and SK2 genes is tightly orchestrated. We therefore evaluated the presence of functional SK2

channels in Pou $4 f 3-\alpha 10$ transgenic mice by promoting $\mathrm{Ca}^{2+}$ influx through voltage-dependent $\mathrm{Ca}^{2+}$ channels. When immature P9 IHCs from wild-type mice were depolarized for $4 \mathrm{~s}$ from a holding potential of $-84 \mathrm{mV}$ (Fig. 5A) using $1 \mathrm{mM}$ EGTA as the intracellular $\mathrm{Ca}^{2+}$ buffer and $1.3 \mathrm{mM}$ extracellular $\mathrm{Ca}^{2+}$, a slowly activating outward current was evident (Fig. 5B, left panel, black traces). Extracellular application of $300 \mathrm{nM}$ apamin, a selective SK2 channel blocker (Kohler et al. 1996), abolished this slowly activating outward $\mathrm{K}^{+}$current (gray traces in Fig. 5B and traces shown in Fig. 5C, left panels: here, records in the presence of apamin were subtracted from control records, leaving only the apamin sensitive current; $n=9$ cells, 9 animals), suggesting that this current was due to the activation of SK2 channels as a result of $\mathrm{Ca}^{2+}$ influx through voltage-gated calcium channels. After the onset of hearing, this current is no longer evident (Fig. 5B, C, middle panels, $n=5$ cells, 5 animals). As observed in wild-type mice, IHCs of Pou $4 f 3-\alpha 10$ transgenic mice also did not exhibit $\mathrm{Ca}^{2+}$ activated SK2 currents after the onset of hearing ( $n=4$ cells, 4 mice; Fig. 5B, C, right panels). Panels D and E show the magnitude of the apamin-sensitive currents $+16 \mathrm{mV}$ and the amplitude of the apamin-sensitive tail 

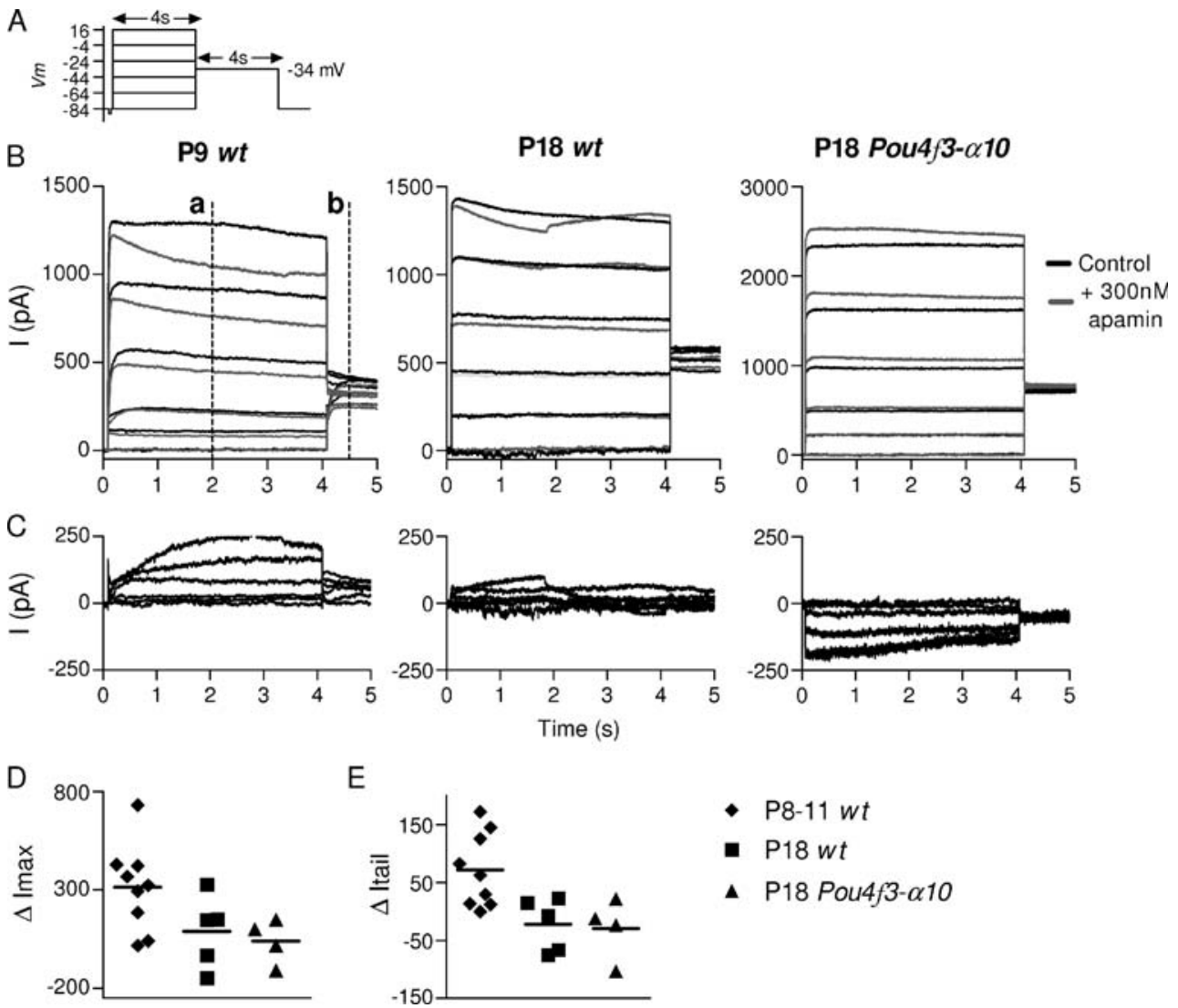

FIG. 5. Lack of functional SK currents in Pou4f3- $\alpha 10$ transgenic mice after the onset of hearing. A Protocol used to measure the slowly activating outward currents in IHCs. Currents were elicited by 4 -s depolarizing voltage steps in $20-\mathrm{mV}$ increments from -84 to $16 \mathrm{mV}$ starting from a holding potential of $-84 \mathrm{mV}$. B Representative outward currents recorded in IHCs in the absence (black traces) or presence (gray traces) of $300 \mathrm{nM}$ apamin in the extracellular solution. Left panel, wildtype responses at P9 ( $n=9$ cells, 9 mice); middle panel, wild-type

currents measured at $2 \mathrm{~s}$ during the depolarizing step (a, in Fig. 5B) and $0.5 \mathrm{~s}$ after it (b, in Fig. 5B), respectively. Whereas at $\mathrm{P} 9$ the magnitude of the SK component was significantly different from zero $(312 \pm 72$ and $72 \pm 21$ at $\mathrm{a}$ and $\mathrm{b}$, respectively, $n=9$ cells, 9 animals, $p \leq 0.01$, Student's $t$ test), at P18, those values did not differ from zero $(p \geq 0.3)$ both for wildtype ( $n=5$ cells, 5 animals) and Pou $4 f 3-\alpha 10$ mice $(n=4$ cells, 4 mice).

\section{DISCUSSION}

Responses of IHCs to ACh prior to the onset of hearing is strictly dependent upon the expression of both the $\alpha 9$ and the $\alpha 10$ nAChR subunits, as demonstrated by the generation of subunit specific null mutant mice (Vetter et al. 2007). Since the expression of the $\alpha 10$, but not that of the $\alpha 9$ subunit, is developmentally regulated (Elgoyhen et al. 2001; responses at P18 ( $n=5$ cells, 5 animals); right panel, responses of Pou4f3- $\alpha 10$ transgenic mice at P18 ( $n=4$ cells, 4 animals). C Subtraction of the currents recorded in the presence of apamin from the total currents reveals the presence of SK2 currents in wild-type mice at P9 and the lack of SK currents at P18 both in wild-type and Pou4f3- $\alpha 10$ transgenic mice. D, E Magnitude of the apamin-sensitive currents at $+16 \mathrm{mV}$ and the amplitude of the tail currents measured at $2 \mathrm{~s}$ during the depolarizing step ( $a$ in $\mathbf{B}$ ) and $0.5 \mathrm{~s}$ after it ( $b$ in $\mathbf{B}$ ), respectively.

Katz et al. 2004), the present work tested the hypothesis that the lack of cholinergic currents in IHCs after the onset of hearing might result from the cessation of the transcription of the Chrnalo gene. To that end, we generated the Pou $4 f 3-\alpha 10$ line of transgenic mice, which drove expression of the $\alpha 10 \mathrm{nAChR}$ subunit after the onset of hearing. Nevertheless, this was not sufficient for the formation of functional $\alpha 9 \alpha 10$ channels, leading to either ACh responses or efferent synaptic currents after P12.

The absence of functional responses after the onset of hearing in the transgenic mice could have alternative explanations. Lack of transcription of the transgene or misexpression of the transgenic RNA can result from the generation of transgenic mice (Haruyama et al. 2009; Su et al. 2004). This is precluded in the case of the Pou4f3- $\alpha 10$ line, since transgenic RNA was present in the cochlea as assessed by RT-PCR and it was localized to the IHC region as demonstrated by in situ hybridization. Alternatively, the $\alpha 10 \mathrm{cDNA}$ plasmid 
used to engineer the transgene construct could have led to a non-functional $\alpha 10$ protein subunit, particularly since a FLAG tag was added before the stop codon of the cDNA. However, this was not the case since the Pou $4 f 3-\alpha 10$ transgene rescued the $\alpha 10$ null phenotype, demonstrated by the presence of normal responses to ACh and synaptic currents in the Pou 4f3$\alpha 10 \times \mathrm{Chrma}^{-10^{-}}$backcross, thus indicating that in vivo, the transgenic $\alpha 10$ subunit efficiently assembles with the endogenous $\alpha 9$ to form functional channels. Importantly, taken together, these results indicate that lack of cholinergic responses of IHCs after the onset of hearing goes beyond the transcription of the Chrna10 gene.

The possibility exists that after the onset of hearing, genes other than Chrna10 also cease transcription and/or translation and that these genes lead to proteins which form part of a macromolecular synaptic complex that includes, but extends beyond the nAChR and which is necessary for assembly, trafficking and/or anchorage of the nAChR to the plasma membrane at the base of the IHC. For example, RIC-3, a transmembrane protein which acts as a molecular chaperone, is required for efficient receptor folding, assembly, and functional expression of the $\alpha 7$ nAChR (Millar 2008). Similar chaperon proteins have not been described in the case of $\alpha 9 \alpha 10$ receptors. However, it is known that activation of the $\alpha 9 \alpha 10 \mathrm{nAChR}$ leads to an increase in intracellular $\mathrm{Ca}^{2+}$ and the subsequent opening of small conductance $\mathrm{Ca}^{2+}$-activated $\mathrm{K}^{+}$SK channels, thus leading to hyperpolarization of hair cells (Dulon et al. 1998; Fuchs and Murrow 1992; Housley and Ashmore 1991; Oliver et al. 2000). Moreover, SK channels and $\alpha 9 \alpha 10$ are known to co-localize in the same functional microdomain, and through such close coupling, the gating kinetics of the SK channels determine the time course of synaptic action, outlasting the driving calcium signals (Oliver et al. 2000). In addition, through the generation of a KCNN2 (gene coding for the SK2 protein) knockout mice, it has been demonstrated recently that the $K C N N 2$ gene is solely responsible for encoding this class of small conductance, calciumactivated potassium channel in cochlear hair cells (Johnson et al. 2007; Kong et al. 2008) and that it cannot be replaced by the later developmental arrival of rapidly activating, iberiotoxin-sensitive "BK"-type potassium channels shown in mammals (Hafidi et al. 2005; Kros et al. 1998; Langer et al. 2003) and birds (Fuchs and Sokolowski 1990). The present results demonstrate that as observed in wild-type mice, the Pou $4 f 3-\alpha 10$ transgenic also lack functional SK2 currents after the onset of hearing. This observation, together with the fact that KCNN2 knockout mice totally lack ACh responses in hair cells (Johnson et al. 2007; Kong et al. 2008), might indicate the SK2 protein as fundamentally required for the assembly, trafficking, and/or anchorage of the nAChR macromolecular synaptic complex. Alternatively, proteins known to form a macromolecular complex with SK2 channels, such as calmodulin, protein kinase CK2, and protein phosphatase 2A (Bildl et al. 2004), might also be developmentally regulated and be the linking molecules of the SK2 channel with the nAChR macromolecular complex.

Although the lack of ACh responses in the KCNN2 knockout mice points towards the SK2 protein as a key player, the fact that in these mice a concomitant OC fiber degeneration is also observed (Kong et al. 2008; Murthy et al. 2009) does not allow an unequivocal conclusion. Thus, lack of pre-and postsynaptic cross talk in the absence of innervation, rather than lack of the SK2 protein as a stabilizing component of the macromolecular synaptic complex, could also lead to the same result. The need of presynaptic neuronal input for the correct assembly of the postsynaptic apparatus has been described at the neuromuscular junction where motor nerve terminals seem to organize postsynaptic differentiation by releasing a proteoglycan called agrin. Agrin activates a receptor tyrosine kinase called musclespecific kinase on the myotube surface, which leads to clustering of nAChRs and other postsynaptic components through association with the cytoplasmic linker protein rapsyn (Sanes and Lichtman 2001).

Finally, we cannot preclude the possibility of a developmental regulation of the translation of the $\alpha 10$ mRNA, which might prevent $\alpha 10$ protein synthesis after the onset of hearing. Emerging studies show that translational control in eukaryotic cells is critical for gene regulation during nutrient deprivation and stress, development and differentiation, nervous system function, aging, and disease (Sonenberg and Hinnebusch 2009). For example, microRNAs are major regulators of gene expression and function at the posttranscriptional level (Carthew and Sontheimer 2009). Further work is required in order to dissect the alternative possibilities proposed as the underlying mechanisms for the developmental regulation of the cholinergic responses of IHCs.

\section{ACKNOWLEDGMENTS}

The authors want to thank the laboratory of Marcelo Rubinstein at INGEBI for generating the transgenic mouse line. This work was supported by the National Institutes of Deafness and other Communication Disorders (NIDCD) grant R01DC001508 to P.A.F. and A.B.E, an International Research Scholar Grant from the Howard Hughes Medical Institute, The National Organization for Hearing Research, a Research Grant from ANPCyT (Argentina), and a Grant from the University of Buenos Aires (Argentina) to A.B.E., NIDCD R01DC006258 to D.E.V, and a CONICET grant to EK. 


\section{REFERENCES}

Bildl W, Strassmaier T, Thurm H, Andersen J, Eble S, Oliner D, Knipper M, Mann M, Schulte U, Adelman JP, Fakler B. Protein kinase CK2 is coassembled with small conductance $\mathrm{Ca}(2+)$ activated $\mathrm{K}^{+}$channels and regulates channel gating. Neuron 43:847-858, 2004

Carthew RW, Sontheimer EJ. Origins and mechanisms of miRNAs and siRNAs. Cell 136:642-655, 2009.

Dulon D, Luo L, Zhang C, Ruan AF. Expression of small-conductance calcium-activated potassium channels (SK) in outer hair cells of the rat cochlea. Eur. J. Neurosci 10:907-915, 1998.

Elgoyhen AB, Johnson DS, Boulter J, Vetter DE, Heinemann S. $\alpha 9$ : an acetylcholine receptor with novel pharmacological properties expressed in rat cochlear hair cells. Cell 79:705-715, 1994.

Elgoyhen AB, Vetter D, Katz E, Rothlin C, Heinemann S, Boulter J. Alpha 10: A determinant of nicotinic cholinergic receptor function in mammalian vestibular and cochlear mechanosensory hair cells. Proc. Natl. Acad. Sci. U. S. A 98:3501-3506, 2001.

Erkman L, McEviliy RJ, Luo L, Ruan AK, Hooshmand F, O'Connell SM, Keithley EM, Rapaport DH, Ryan AF, Rosenfeld MG. Role of transcription factors Brn-3.1 and Brn-3.2 in auditory and visual system development. Nature 381:603-606, 1996.

Fuchs PA, SoкоLowski BH. The acquisition during development of Ca-activated potassium currents by cochlear hair cells of the chick. Proc. Biol. Sci 241:122-126, 1990.

Fuchs PA, Murrow BW. Cholinergic inhibition of short (outer) hair cells of the chick's cochlea. J. Neurosci 12:800-809, 1992.

Glowatzki E, Fuchs P. Cholinergic synaptic inhibition of inner hair cells in the neonatal mammalian cochlea. Science 288:23662368, 2000.

Gomez-Casati ME, Fuchs PA, Elgoyhen AB, Katz E. Biophysical and pharmacological characterization of nicotinic cholinergic receptors in cochlear inner hair cells. J. Physiol 566:103-118, 2005.

Guinan JJ. Physiology of olivocochlear efferents. In: Dallos P, Popper A, Fay R (eds) The Cochlea. New York, Springer, pp. 435-502, 1996.

Hafidi A, Beurg M, Dulon D. Localization and developmental expression of BK channels in mammalian cochlear hair cells. Neuroscience 130:475-484, 2005.

Haruyama N, Cho A, Kulkarni AB. Overview: Engineering transgenic constructs and mice. Current Protocols in Cell Biology, Chapter 19, Unit 19.10, 2009.

Hiel H, Elgoyhen A, Drescher D, Morley B. Expression of nicotinic acetylcholine receptor mRNA in the adult rat peripheral vestibular system. Brain. Res 738:347-352, 1996.

Housley GD, Ashmore JF. Direct measurement of the action of acetylcholine on isolated outer hair cells of the guinea pig cochlea. Proc. R. Soc. Lond. B 244:161-167, 1991.

Johnson SL, Adelman JP, Marcotti W. Genetic deletion of SK2 channels in mouse inner hair cells prevents the developmental linearization in the $\mathrm{Ca}^{2+}$ dependence of exocytosis. J. Physiol 583:631-646, 2007.

Katz E, Elgoyhen AB, Gomez-Casati ME, Kniper M, Vetter DE, Fuchs PA, GLOWATZKI E. Developmental regulation of nicotinic synapses on cochlear inner hair cells. J. Neurosci 24:7814-7820, 2004.

Kohler M, Hirschberg B, Bond CT, Kinzie JM, Marrion NV, Maylie J, Adelman JP. Small-conductance, calcium-activated potassium channels from mammalian brain. Science 273:1709-1714, 1996.

Kong JH, Adelman JP, Fuchs PA. Expression of the SK2 calciumactivated potassium channel is required for cholinergic function in mouse cochlear hair cells. J. Physiol 586:5471-5485, 2008.

Kros CJ, Ruppersberg JP, Rusch A. Expression of a potassium current in inner hair cells during development of hearing in mice. Nature 394:281-284, 1998.
Langer P, Grunder S, Rusch A. Expression of $\mathrm{Ca}^{2+}$-activated BK channel mRNA and its splice variants in the rat cochlea. J. Comp. Neurol 455:198-209, 2003.

Lustig LR, Peng H, Hiel H, Yamamoto T, Fuchs P. Molecular cloning and mapping of the human nicotinic acetylcholine receptor $\alpha 10$ (CHRNA10). Genomics 73:272-283, 2001.

Marcotti W, Johnson SL, Holley MC, Kros CJ. Developmental changes in the expression of potassium currents of embryonic, neonatal and mature mouse inner hair cells. J. Physiol 548:383400, 2003a.

Marcotti W, Johnson SL, Rusch A, Kros CJ. Sodium and calcium currents shape action potentials in immature mouse inner hair cells. J. Physiol 552:743-761, 2003b.

MilLaR NS. RIC-3: A nicotinic acetylcholine receptor chaperone. Br. J. Pharmacol 153(Suppl 1):S177-S183, 2008.

Morley BJ, Simmons DD. Developmental mRNA expression of the alpha10 nicotinic acetylcholine receptor subunit in the rat cochlea. Brain Res. Dev. Brain Res 139:87-96, 2002.

Murthy V, Maison SF, Taranda J, Haque N, Bond CT, Elgoyhen AB, Adelman JP, Liberman MC, VetTer DE. SK2 channels are required for function and long-term survival of efferent synapses on mammalian outer hair cells. Mol. Cell. Neurosci 40:39-49, 2009.

Oliver D, Klocker N, Schuck J, Baukrowitz T, Ruppersberg JP, Fakler B. Gating of $\mathrm{Ca}^{2+}$-activated $\mathrm{K}^{+}$channels controls fast inhibitory synaptic transmission at auditory outer hair cells. Neuron 26:595-601, 2000.

Plazas PV, Katz E, Gomez-Casati Me, Bouzat C, Elgoyhen AB. Stoichiometry of the $\alpha 9 \alpha 10$ nicotinic cholinergic receptor. J Neurosci 25:10905-10912, 2005.

Sage C, Huang M, Vollrath MA, Brown MC, Hinds PW, Corey DP, Vetter DE, Chen ZY. Essential role of retinoblastoma protein in mammalian hair cell development and hearing. Proc. Natl. Acad. Sci. U. S. A 103:7345-7350, 2006.

SAnes JR, Lichtman JW. Induction, assembly, maturation and maintenance of a postsynaptic apparatus. Nat. Rev. Neurosci 2:791-805, 2001.

Sgard F, Charpentier E, Bertrand S, Walker N, Caput D, Graham D, Bertrand D, Besnard F. A novel human nicotinic receptor subunit, $\alpha 10$, that confers functionality to the $\alpha 9$-subunit. Mol. Pharmacol 61:150-159, 2002.

Simmons DD. Development of the inner ear efferent system across vertebrate species. J. Neurobiol 53:228-250, 2002.

SONENBERg N, HinNebusch AG. Regulation of translation initiation in eukaryotes: Mechanisms and biological targets. Cell 136:731745, 2009

Su M, Hu H, Lee Y, d’Azzo A, Messing A, Brenner M. Expression specificity of GFAP transgenes. Neurochem. Res 29:2075-2093, 2004.

Vetter De, Katz E, Maison SF, Taranda J, Turcan S, Ballestero J, Liberman MC, Elgoyhen AB, Boulter J. The alpha10 nicotinic acetylcholine receptor subunit is required for normal synaptic function and integrity of the olivocochlear system. Proc. Natl. Acad. Sci. U. S. A 104:20594-20599, 2007.

Walsh E, McGee J, McFadden S, Liberman M. Long-term effects of sectioning the olivocochlear bundle in neonatal cats. J. Neurosci 18:3859-3869, 1998.

Weisstaub N, Vetter D, Elgoyhen A, Katz E. The alpha9/alpha10 nicotinic acetylcholine receptor is permeable to and is modulated by divalent cations. Hearing. Res 167:122-135, 2002.

Young Ji, Otero V, Cerdan MG, Falzone TL, Chan EC, Low MJ, Rubinstein M. Authentic cell-specific and developmentally regulated expression of pro-opiomelanocortin genomic fragments in hypothalamic and hindbrain neurons of transgenic mice. J. Neurosci 18:6631-6640, 1998. 